not a thermometer with me). It was a warm summer's dayJuly 23. The ice exhibited the usual prismatic structure, but the prisns seldom exceeded a third of an inch in diameter. I was informed that in winter it was choked up with snow. The other finorme also contained ice, but as it was less accessible, and secmed in no way different from the former, I did not enter it. The especial interest of this case is that it affords what I might call the most rudimentary type of a glaciere; a natural icehouse, replenished every winter, and perhaps sometimes entirely cleared out during an unusually hot summer. The "Grotto" on Monte Tofana, near the Ampezzo Pass (which I have not been able to visit), is, I expect, another of this kind.

St. John's College, Cambridge

T. G. BONNEY

[By a misprint "glacier" was put for glacière in the last para. graph of Mr. Ward's paper. - ED. ]

\section{The Morse Code}

THE following mremonical device may be of some use to young telegraph students, and others, who wish to commit the Morse alphabet to memory. There is, I believe, a device employed in the Government schools, but it gives one so little help that I lately jotted down the subjoined scheme for my own instruction.

Let the vowels $a$ e io $u$ and also $s / 2$ represent the dots, and the remaining leiters of the alphabet the dashes in the Morse code: the word attached to each letter will then express the signal for that letter. These words must be learnt; a task rendered easy by their commencing with or containing the letter they signisfy.

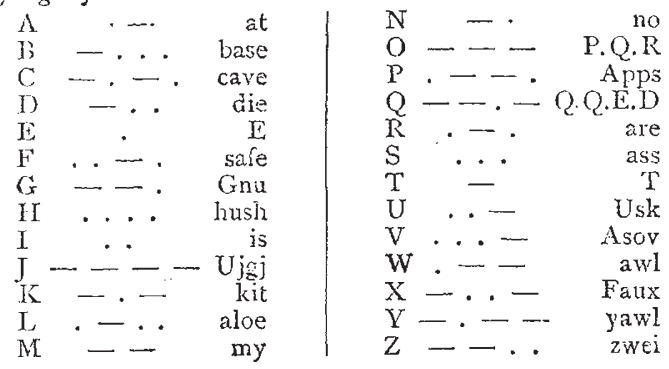

A few of the letters, e.g. J (the word for which might be regarded as a new way of spelling Ujiji), $\mathrm{O}$, and $\mathrm{Q}$, present a little difficulty, which some of your readers may lessen. As it is, these exceptional cases are so quickly impressed on the memory that the code thus learnt can be written in a surprisingly short time, and read soon afterwards. It is hardly possible the plan here suggested can be rew, yet, as I have not met with anything similar, I venture to send it to you for publication.

\section{W. F. BARRETT}

The Micrographic Dictionary-Pollen Grains AT present $I$ have to do with the "Micrographic Dictionary" and the two other works mentioned in my letter printed in Nature, vol.xi., p. 286 . If the pollen grains of Mimulus moschatus are variable (as now stated by $\mathrm{Mr}$. Cooke on the authority of Dr. Mohl), how is it that the figures and descriptions in the books mentioned are ail alike? There is no variability here, but wonderful sameness both in illustrations and letter-press.

As the accuracy of my first simple observation has been called in question, I will add another. In the "Micrographic Dictionary," $\mathrm{P}$. 32, Fig. 28 , is given the pollen of Sonchus palustris. This, like that of the Mimulus, is totally wrong, the reticulation is by no means correct, and the aburdant spines with which this pollen grain is clad (so common in the Compositæ) are totally omitted. Now, on turning to the Rev. J. G. Wood's book, PI. 3, Fig. 24, this erroneous figure is reproduced with incorrect reficulation and no spines, and on referring to $\mathrm{Mr}$. Cooke's work, Pl. 2, Fig. 6, the same errors are again perpetrated.

W. G. SMITH

\section{OUR ASTRONOMICAL COLUMN}

$\zeta^{1}$ AND $\zeta^{2}$ RETICULI.-These stars of about the sixth magnitude appear to offer a similar instance of large and nearly equable proper motion to the well-known one afforded by 36 Ophiuchi and 30 Scorpii, which was first pointed out by Bessel in the "Fundamenta Astronomize." If we compare Lacaille's positions (taking them from the reduced catalogue published by the British Association) with those given by the late Capt. Jacob from the Madras observations 1853-57, we find with the Pulkova precessions-

$$
\begin{aligned}
& \text { Secular Proper Motion. Direction of }
\end{aligned}
$$

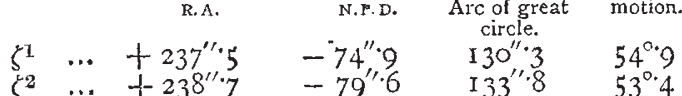

The introduction of Brisbane's places would only modify the above figures in 2 trifling degree.

When competent observers in the southern hemisphere are provided with heliometers for research on stellar aarallax, there will be no lack of objects to occupy their pttention, and we may expect most important results from such investigations.

THE BINARy StaR $\eta$ CASSiopere. We may very soon be able to make a fair approximation to the orbit of this double star, and so, with Mr. Otto Struve's value for the annual parallax, form some idea of the real dimensions and mass of the system, as is already the case with $a$ Centauri and 70 Ophiuchi. An orbit given by Mr. Powell, of Madras, in vol, xxi. of Monthly Notices, R. A. S., is probably vitiated by typosraphical error or errors. Struve's parallax is $O^{\prime \prime} \cdot 154 \pm 0^{\prime \prime} \circ 45$.

THE BINARY STAR a CENTAURr.-According to Mr. Powell's last elements, which are founded on measures up to 1870 inclusive, the components, at the present time, are nearly at their minimum apparent distance $\left(\mathrm{I}^{\prime \prime} \cdot 2\right)$, and the angle of position is advancing at the rate of $10^{\circ}$ monthly. It may be hoped this fine object is receiving due attention from astronomers in the southern hemisphere at this critical period of the revolution. There would appear to be no probability of such difficulties attending observations at the passage of the peri-astron as those presented by $\gamma$ Virginis in 1836 , so far at least as can be judged from the measures to 1870 .

RED STARS.-Amongst the red stars notified by the late M. Chacornac, is one which he estimated between the seventh and eighth magnitude, and of which he says, "éclat terne et nebuleuse." The position assigned identifies the star with No. II72 of Rümker's Catalogue, whence for the commencement of the present year its right ascension is $4 \mathrm{~h}$. $16 \mathrm{~m}$. I6s., and polar distance $67^{\circ} 19^{\prime} \%$. Rümker calls it a sixth magnitude, and Argelander (Durchmusterung) an eighth. Although different eyes will not always agree in estimations of brightness of the ruddy stars, there appears here to be a suspicion of variable light. Another of Chacornac's isolated red stars he himself indicates as variable. It is Oeltzen 21356, called 6 mag. by Lalande (No. 4I453), 5.6 by Argelander, 5 in the Washington Zone, 1848 , July 24 ; while Chacornac remarks, "sometimes brighter and sometimes fainter than a star of the seventh magnitude near it," which is probably Oeltzen 21386. Position for I875, R.A. 2 xh. 17m. 5s.; P.D., III $22^{\prime} 7$. Neither of these stars is in Schjellerup's Catalogue, but that list is very far from being a conplete one.

ENCKE'S COMET.-The extreme faintness of this comet at the present appearance is attracting the attention of astronomers who have had most experience of the circumstances of previous returns. Last week we quoted the remark of M. Stéphan on this subject, and we learn from him that he was using a newly polished mirror in the great Foucault telescope of the Observatory of Marseilles. In 1868 and 1871 the comet's appearance was very similar to what it had been in previous years under analogous conditions. In discussing the probability of any real change in the comet's constitution, it may, however, be well to bear in mind that in the year 1842 , when the peri- 